\title{
Editorial
}

\section{A New Editorial Office in Qingdao, a New E-Publishing System for MDPI Journals and Beilstein Starts Coverage of Molecules.}

\author{
Shu-Kun Lin ${ }^{1,2}$, Derek J. McPhee ${ }^{3}$ and Francis F. Muguet ${ }^{4}$ \\ ${ }^{1}$ Molecules Editorial Office, Ocean University of China, Qingdao 266003, Shandong Province, China. \\ Tel. \& Fax: (+86) 532203 1522; Tel.: (+86) 5322031860 (office direct); E-mail: \\ linsk@ouqd.edu.cn. \\ ${ }^{2}$ Molecular Diversity Preservation International (MDPI), Matthaeusstrasse 11, CH-4057 Basel, \\ Switzerland. Tel.: (+41) 79322 3379; Fax: (+41) 61302 8918; E-mail: lin@mdpi.org; Webpage: \\ http://www.mdpi.org/lin. \\ ${ }^{3}$ Brantford Chemicals Inc., 34 Spalding Dr., Brantford, ON, N3T 5W5, Canada. Tel.: (+1) $519756-$ \\ 8942, xt 4992; Fax: (+1) 519 753-3051; E-mail: mcphee@ mdpi.org. \\ ${ }^{4}$ Laboratoire de Mathématiques Appliquées, ENSTA (Ecole Nationale Superieure de Techniques \\ Avancees), 32 Boulevard Victor, F-75739 Paris Cedex, France. Tel.: (+33) 1.45.52.60.19; Fax: (+33) \\ 1.45.52.52.82; E-mail: muguet@ensta.fr; Webpage: http://www.ensta.fr/ muguet.
}

During the past six months, updating of Molecules webpages has occasionally been delayed, some papers may have been published somewhat slower than usual and our communications with the Molecules community has been less frequent, but these facts do not mean we have been paying less attention to our flagship journal Molecules (ISSN 1420-3049) and the http://www.mdpi.org/molecules/ website. Rather, since May 2002, and in order to greatly enhance the editorial manpower and editorial technology, we have been busy setting up a new Editorial Office in Qingdao, China [1] and developing and testing a new e-publishing system [2]. During this period we also prepared and hosted a very successful international conference, the International Symposium on Frontiers in Molecular Science 2002 (ISFMS 2002), Qingdao, China, July 15-18, 2002 [3]. Immediately after the conference, and thanks to the great support of the Ocean University of China [4], the Editorial Office in Qingdao has started to function.

During the ISFMS 2002 conference, chemists active in the virtual editorial center, particularly three of us (Shu-Kun from Switzerland, Derek from Canada and Francis from France), met to discuss various editorial issues concerning Molecules. After the conference, Francis kindly remained at the 
Ocean University of China to install and test a new Linux server. This will be the mirror for the Linux server at the University of Basel, Switzerland, hosting the SciForum.Net at the http://www.sciforum.net/ website.

Between July 20 - August 20, 2002, office equipment was purchased and installed, including five workstation terminals and two servers (the Linux mirror server of the one at Basel, Switzerland, and an NT server for the virtual editorial center and the Editorial Office). Our connection to the Internet is now very fast. There are currently five full-time editorial staff members working at the editorial office at the Ocean University of China. Two of them will be responsible for maintaining the new network, the Linux server in Basel, and for developing and improving the e-publishing system. With the addition of more staff, we hope to establish and maintain improved editorial procedures [5]. Accepted papers will now be published immediately and we expect to be able to published more papers per issue in the near future. Shu-Kun Lin also was appointed as a full professor at the Ocean University of China and has started to enroll graduate students to do research on the e-publishing system database. According to the terms of our agreement, MDPI will remain as the publisher of Molecules. We also plan to produce printed issues in 2003 in collaboration with the Ocean University of China, at the same time that we produce archival issues of Molecules and some of its sister journals - Entropy and the International Journal of Molecular Sciences [6].

On August 20, 2002, Professor Hua-Shi Guan, the president of the Ocean University of China and Professor Shu-Kun Lin, the Editor-in-Chief of Molecules, held an opening ceremony for the Editorial Office at the Ocean University of China. Professor Hua-Shi Guan has kindly agreed to be the Honorary Editor-in-Chief of Molecules.

As our readers know, papers published in Molecules - the first fully electronic journal dedicated to Synthetic Organic Chemistry - are fully and promptly indexed and abstracted by all the leading indexing and abstracting services, including Chemical Abstracts (CAPLUS); Science Citation Index Expanded; SciSearch, Research Alert; Chemistry Citation Index and Current Contents, Index Medicus and MEDLINE. In a new development, as of last year Beilstein [7] has also started to cover papers published in Molecules, which has thus become one of the nearly 180 journals indexed for the Beilstein Database [8]. As synthetic organic chemists, we are all aware of the prestige and importance of Beilstein, which in recent years has also become available in an online database form: Crossfire Beilstein, containing the complete Beilstein Database of organic chemical compounds, covering over 8 million compounds and 5 million chemical reactions dating back to 1771 .

At Molecules we will continue to maintain the highest editorial standards in addition to a very fast publishing procedure. The deposit and exchange services for authentic samples will also be continued through MDPI [9]. As always, the editorial staff welcomes reader's comments on these or any other issues concerning Molecules and its operation. 


\section{References and Notes}

1. Mailing address: Molecules Editorial Office, Ocean University of China, Qingdao 266003, Shandong Province, P. R. China. Tel \& Fax: (+86) 532203 1522; Tel.: (+86) 5322031860 (office direct line); E-mail: molecules@ouqd.edu.cn; Webpages: http://www.mdpi.org/molecules or http://molecules.ouqd.edu.cn/.

2. Many of the features for the online submission of manuscripts, online editorial work and refereeing process have already been installed at the http://www.mdpi.net/ej website, and are currently undergoing an exhaustive testing process. The complete e-publishing system will be used for the SciForum.Net project (http://www.sciforum.net/) and will be installed there within 6 months.

3. See the preceding Commentary: The International Symposium on Frontiers in Molecular Science 2002 (ISFMS 2002), Qingdao, China, July 15-18, 2002.

4. In late 2002 the Ocean University of Qingdao was officially renamed Ocean University of China.

5. Lin, S.-K. Editorial: A Good Yield and a High Standard. Molecules 1996, 1, 1-2.

6. See the following Editorial: New Development: A Printed Edition.

7. Website for Belstein and CrossFire Beilstein: http://www.beilstein.com/.

8. Journals Indexed for the Beilstein Database: http://www.beilstein.com/beilst 5.shtml.

9. See the http://www.mdpi.org/index-samples.htm webpage.

(C) 2002 by MDPI (http://www.mdpi.org). Reproduction is permitted for noncommercial purposes. 